\title{
Experimental Study on the Ultimate Shear Performance of Elastomeric Bearings of Doublefold Elastomeric Layer
}

\author{
Hyejin Yoon, Im Jong Kwahk, Young Jin Kim \\ Structural Engineering Research Division, Korea Institute of Construction Technology, Goyang, South Korea \\ Email: hiyoon@kict.re.kr, kwakim@kict.re.kr, yjkim@kict.re.kr
}

Received November 10, 2012; revised December 8, 2012; accepted December 19, 2012

\begin{abstract}
The elastomeric bearings shall not fail nor degrade the durability of the bridge due to the loss of its properties during its service life. Since the elastomeric bearings can be used in the seismic design complementarily to seismic devices, even if it is not a seismic isolator, they particularly should secure high shear performance. For elastomeric bearings to behave monolithically, the internal rubber which is located between the steel plates should be single rubber layer. In this study, a series of elastomeric bearings were fabricated and ultimate shear performance was investigated. Some specimens are of single elastomeric layer, the other are of doublefold elastomeric layer. Shear fatigue tests and ultimate shear tests were carried out. Tests results show that the elastomeric bearings whose internal rubber layer is formed by agglomeration of several rubber pads is likely to experience significant loss of its shear performance or early failure.
\end{abstract}

Keywords: Elastomeric Bearings; Shear Performance; Shear Fatigue Test; Ultimate Shear Test

\section{Introduction}

The Elastomeric bearings are a laminated structure combining rubber and stiffening plate layers. They transfer the loads of the superstructure to the substructure and also absorb the movements of the superstructure caused by loading, creep, thermal change and drying shrinkage. In Korea, the Korean Industrial Standard KS F 4420 (KS) specifies requirements for the design, performance evaluation and fabrication of the elastomeric bearings [1]. For elastomeric bearings to behave monolithically, the internal rubber which is located between the steel plates should be the single rubber layer. In Korea, elastomeric bearings of doublefold elastomeric layer are common practice, because the current KS doesn't restrict the use of doublefold elastomeric layer. Besides, since the performance of the elastomeric bearings designed in compliance with KS are not passing through the certification system of an authorized agency but rely on the in-house performance evaluation of the manufacturer, the lack of data enabling to verify objectively the performances is worrisome.

In this paper eastomeric bearings are fabricated in compliance with KS and their ultimate shear performances were investigated. Some specimens are of single elastomeric layer, the other are of doublefold elastomeric layer. The significant degradation of the shear performances of the elastomeric bearings fabricated by means of the common practice in Korea is revealed and directions enabling to improve these performances are suggested.

\section{Fabrication of Specimens}

A series of elastomeric bearings were designed and fabricated in compliance with KS. KS presents 6 types of elastomeric bearings. The adopted elastomeric bearings is of type B with outer steel plate of KS exhibiting a shear modulus of 0.9. It is a monolithic structure obtained by vulcanization of the rubber pad and external steel plates. Specimens were classified into S5 and S10. Specimen S5 has the doublefold elastomeric layer. Specimen S10 adopted the single elastomeric layer. The shapes and dimensions of the fabricated elastomeric bearings are presented in Figures $\mathbf{1}$ to $\mathbf{2}$ and in Table $\mathbf{1}$.

\section{Shear Performance Test}

\subsection{Test Machine}

Figure 3 shows a test machine. It can apply simultaneously vertical and horizontal loads. The capacity of the vertical actuator of the bearing testing device is a maximum load of $3500 \mathrm{kN}$ and a stroke of $350 \mathrm{~mm}$. The capacity of the horizontal actuator is a maximum load of $500 \mathrm{kN}$ and a stroke of $700 \mathrm{~mm}$.

\subsection{Shear Fatigue Test}

Most of the design codes limit a total shear strain of the elastomeric bearings in order to prevent failure due to the 

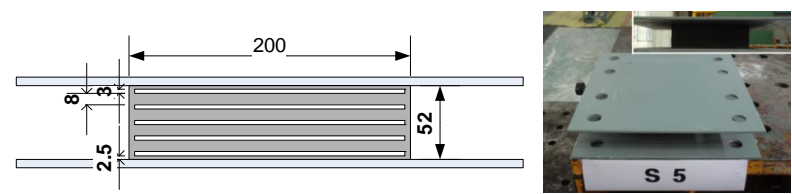

Figure 1. Specimens S5.

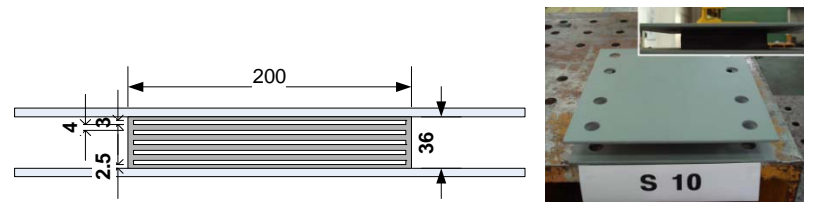

Figure 2. Specimens S10.

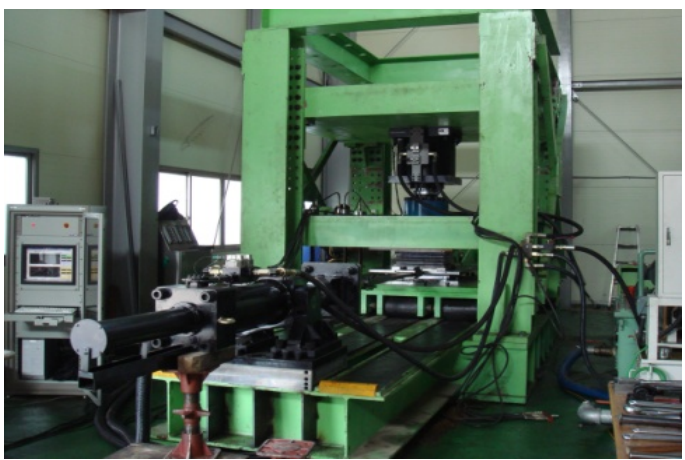

Figure 3. Test machine.

Table 1. Dimensions of the elastomeric bearing specimens.

\begin{tabular}{|c|c|c|c|c|}
\hline \multicolumn{2}{|c|}{ Item } & Units & \multicolumn{2}{|c|}{ Dimensions } \\
\hline \multirow{2}{*}{ Bearing } & Width & $\mathrm{a}(\mathrm{mm})$ & \multicolumn{2}{|c|}{150} \\
\hline & Length & $\mathrm{b}(\mathrm{mm})$ & \multicolumn{2}{|c|}{200} \\
\hline \multirow{4}{*}{$\begin{array}{l}\text { Stiffening } \\
\text { plate }\end{array}$} & Width & $\mathrm{a}^{\prime}(\mathrm{mm})$ & \multicolumn{2}{|c|}{142} \\
\hline & Length & $\mathrm{b}^{\prime}(\mathrm{mm})$ & \multicolumn{2}{|c|}{192} \\
\hline & Thickness & $t_{s}(\mathrm{~mm})$ & \multicolumn{2}{|c|}{3} \\
\hline & Layers & & \multicolumn{2}{|c|}{5} \\
\hline \multirow{2}{*}{\multicolumn{2}{|c|}{$\begin{array}{l}\text { Thickness of internal } \\
\text { rubber layer }\end{array}$}} & \multirow{2}{*}{$t_{r}(\mathrm{~mm})$} & S5 & 8 \\
\hline & & & $\mathrm{S} 10$ & 4 \\
\hline \multirow{2}{*}{\multicolumn{2}{|c|}{ Height of rubber layer }} & \multirow{2}{*}{$T_{r}(\mathrm{~mm})$} & S5 & 37 \\
\hline & & & $\mathrm{S} 10$ & 21 \\
\hline \multicolumn{2}{|c|}{ Shear modulus } & $G(\mathrm{MPa})$ & \multicolumn{2}{|c|}{0.9} \\
\hline \multirow{2}{*}{\multicolumn{2}{|c|}{ Shape factor }} & \multirow{2}{*}{$S$} & S5 & 5.10 \\
\hline & & & $\mathrm{S} 10$ & 10.20 \\
\hline
\end{tabular}

shear fatigue of the bearing. The total shear strain consider the shear strain caused by compressive load, rotation and shear force (Figure 4). KS prescribes the total strain to be smaller than $500 \%$ of the total height of the rubber of the bearing (Equation (1)).

$$
\gamma_{t}=\gamma_{c}+\gamma_{s}+\gamma_{\alpha} \leq 5.0
$$

Shear fatigue tests were carried out on 3 specimens in

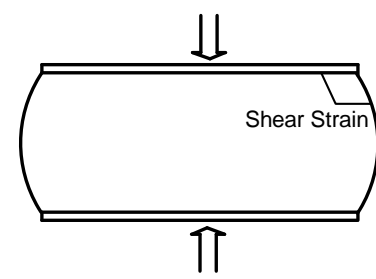

(a)

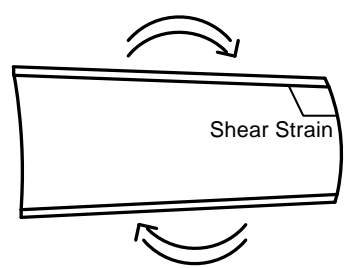

(b)

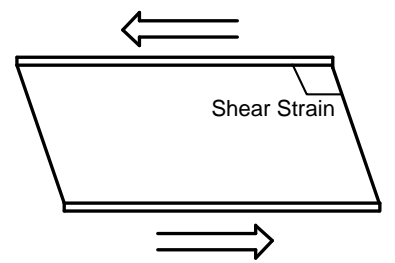

(c)

Figure 4. Total shear strain of elastomeric bearing $\left(\gamma_{t}\right)$. (a) Shear strain due to compression $\left(\gamma_{c}\right)$; (b) Shear strain due to rotation $\left(\gamma_{\alpha}\right)$; (c) Shear strain due to shear force $\left(\gamma_{s}\right)$.

order to examine the fatigue stability of the elastomeric bearing with regard to this total shear strain proposed by KS. The shear fatigue test is a test applying repeatedly shear deformation while maintaining constant vertical stress in the bearing (Figure 5).

Assuming that the bridge has a service life of 50 years, the deformation of the superstructure caused by temperature will experience a total of 18,250 horizontal displacement cycles on a daily average. The shear deformation had thus to be applied at frequency of $0.000116 \mathrm{~Hz}$ in order to reflect it in the shear fatigue test but it was impracticable. Accordingly, the loading speed of the shear deformation was determined as $0.2 \mathrm{~Hz}$ with reference to the example of previous researchers [2,3], and the number of cycles was set to 20,000 cycles instead of the required 18,250 cycles for the execution of the shear fatigue tests.

Table 2 summarizes the shear fatigue test program. In consideration of KS limits the total shear strain to 5.0, the S5 specimens were set to provide a total shear strain near to 5.0. The S10 specimen were designed to produce a total shear strain increased up to 7.41 in order to examine the fatigue behavior of the elastomeric bearing at ultimate state. The effect of the rotation was not considered. The shear strain due to movement was set to a value of 0.7 as proposed by the KS or 0.9 in order to examine the stability for a range larger than KS. 


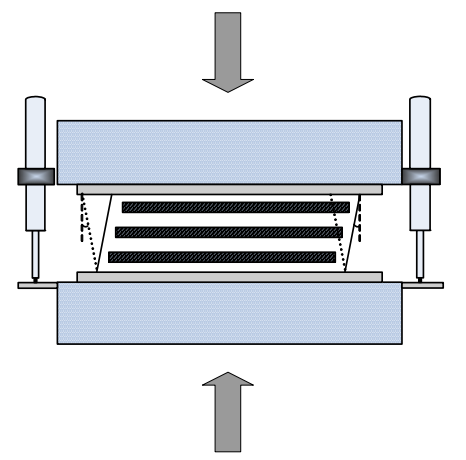

Figure 5. Conceptual scheme of shear fatigue test.

Table 2. Shear fatigue test program.

\begin{tabular}{|c|c|c|c|c|c|c|c|}
\hline \multirow{2}{*}{ Specimen } & \multirow{2}{*}{$\begin{array}{c}\text { Compressive } \\
\text { Stress } \\
{[\mathrm{MPa}]}\end{array}$} & \multicolumn{4}{|c|}{ Shear Strain } & \multirow{2}{*}{$\begin{array}{l}\text { Vertical } \\
\text { load } \\
{[\mathrm{kN}]} \\
\end{array}$} & \multirow{2}{*}{$\begin{array}{c}\text { Horizontal } \\
\text { displacement } \\
{[\mathrm{mm}]}\end{array}$} \\
\hline & & $\gamma_{c}$ & $\gamma_{s}$ & $\gamma_{\alpha}$ & $\gamma_{t}$ & & \\
\hline S5\#4 & 12 & 3.92 & 0.9 & 0 & 4.82 & 270 & 33.3 \\
\hline S5\#5 & 12 & 3.92 & 0.7 & 0 & 4.62 & 283 & 25.9 \\
\hline S10\#6 & 40 & 6.53 & 0.9 & 0 & 7.41 & 983 & 18.9 \\
\hline
\end{tabular}

\subsection{Ultimate Shear Test}

Ultimate shear tests were carried out on 2 specimens in order to examine the shear behavior of the elastomeric bearing at ultimate state. S5\#3 is the specimen of single elastomeric layer and $\mathrm{S} 10 \# 5$ is of doublefold elastomeric layer. Ultimate shear test provoked shear deformation until failure of the bearings while maintaining a constant vertical stress. In order to prevent the possible occurrence of uplift force in the elastomeric bearings, the shear deformation was provoked under application of a load corresponding to the minimum compressive stress of $3 \mathrm{MPa}$ of KS (Table 3). The shear deformation was applied at speed of $0.2 \mathrm{~mm} / \mathrm{sec}$. The horizontal load and horizontal displacement of the bearing were measured. The external appearance was also observed during the ultimate shear test to verify the eventual occurrence of anomalies in the bearing according to the increase of the shear strain. Ultimate shear tests were also conducted for specimens which didn't failed from shear fatigue tests.

\section{Test Results}

\subsection{Shear Fatigue Test}

This study carried out shear fatigue tests to verify the ultimate shear performances of the Korean elastomeric bearings. Various total shear strains were adopted.

The results of the shear fatigue test are summarized in Table 4. The change of the external appearance of the elastomeric bearings according to the number of shear cycles was observed. Specimen S10\#6 adopting single elastomeric layer was set to the highest total strain of 7.41. S10\#6 showed no particular damage or dilatation
Table 3. Ultimate shear test program.

\begin{tabular}{ccc}
\hline Specimen & $\begin{array}{c}\text { Compressive stress } \\
{[\mathrm{MPa}]}\end{array}$ & Shear deformation \\
\hline S5 \#3 & 3 & Until failure \\
S10 \#5 & 3 & Until failure \\
\hline
\end{tabular}

sufficient to provoke their loss of performance after 20,000 cycles.

On the other hand, externally visible damage or failure occurred for all the tested specimens S5, of doublefold elastomeric layer, despite this series of specimens was set to secure a total shear strain below the maximum value of 5.0 of the KS. Observing the specimens for which problems occurred during the shear fatigue tests, early failure occurred for specimen S5\#4 at about 700 cycles (Figure 6). Shear failure of elastomeric bearings generally occurs through debonding that is the separation of the stiffening plates from rubber layers. However, specimen S5\#4 failed by separation following the formation of an interface inside each of the rubber layers. Figure 7 shows the changes of external appearance according to shear cycles. Specimen S5\#5 experienced severe external damage during the shear fatigue test even if the specimen did not fail completely since the applied shear strain due to horizontal movement was smaller than that of specimen S5\#4. The local dilatation of rubber started to appear clearly since 12,000 cycles, worsened with increasing cycles to experience outflow of the internal rubber at 17,000 cycles following the aggravated loss of the vulcanization of the elastic pad and external stiffening plate.

\subsection{Ultimate Shear Test}

This study performed the ultimate shear tests in order to examine the shear behavior of the elastomeric bearings at ultimate state. Figure 8 shows the failure of elastomeric bearings under ultimate shear test. The specimen S10\#5 failed through the tearing of rubber. However, S5\#3 adopting doublefold elastomeric layer exhibited some difference from the common shear failure pattern by tearing of the rubber along the measurement interface in the internal rubber layer.

Figure 9 shows the load-displacement curves of elastomeric bearings under ultimate shear tests. The failure point of the bearing is defined as the point at which the horizontal force is maximum according to the definition of the Japanese Manual for Highway Bridge Bearings [4]. Ultimate shear failure of elastomeric bearings is detected generally in the range of $400 \%-600 \%$ of the height of rubber. From the ultimate shear tests, the reduction of shear performance was observed for the bearing of doublefold elastomeric layer. Specimen S10\#5 failed at shear strain of 493 percent. However, Specimen S5\#3 adopting 
Table 4. Summary of shear fatigue test results.

\begin{tabular}{ccc}
\hline Specimen & $\begin{array}{c}\text { Doublefold } \\
\text { elastomeric layer }\end{array}$ & $\begin{array}{c}\text { Eventual visible damage or } \\
\text { failure }\end{array}$ \\
\hline S5 \#4 & $\circ$ & Failure after 700 cycles \\
S5 \#5 & $\circ$ & Severe visible damage \\
S10 \#6 & $\mathrm{x}$ & No anomaly \\
\hline
\end{tabular}

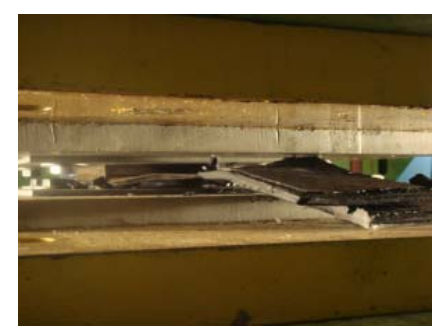

Figure 6. S5\#4 after 700 cycles.

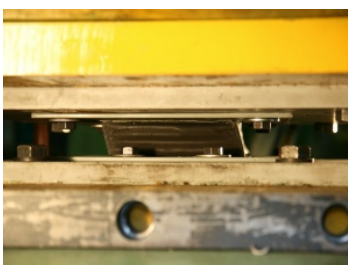

(a)

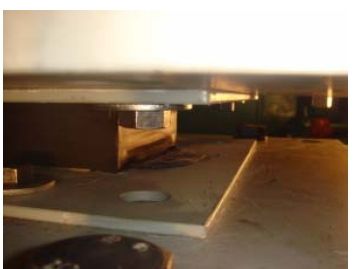

(c)

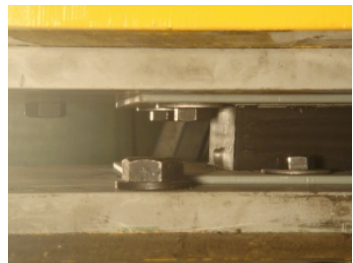

(b)

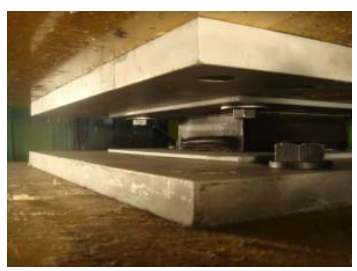

(d)
Figure 7. Change of external appearance according to shear cycles for specimen S5\#5. (a) After 10,000 cycles; (b) After 12,000 cycles; (c) After 17,000 cycles; (d) After 20,000 cycles.

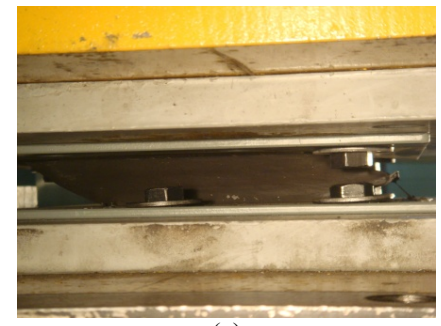

(a)

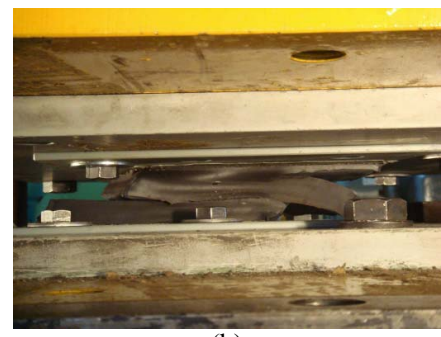

(b)

Figure 8. Shear failure. (a) S10\#5; (b) S5\#3. doublefold elastomeric layer failed at shear strain of 253 percent. Elastomeric bearings of doublefold elastomeric layer exhibit low shear performance.

In the Figure 9 temporary loss of the load could be observed twice before the failure. This can be explained by the occurrence of temporary separation at the surface of contact between the elastic pad and external steel plate as observed during the visual inspection executed during the test. The elastomeric bearings used for the ultimate shear test are bearings fabricated with a monolithic structure combining the elastic pad and external steel plates by vulcanization, which means that the specimens should behave monolithically until the ultimate shear strain. However, these two specimens did not behave monolithically even under very low strain before the failure and experienced temporary separation at the surfaces of contact between the elastic pad and external steel plates. At the time when separation occurred at one of the two surfaces of contact, the shear strain of the elastomeric bearing happened to recover to some extent. Thereafter, it seemed that the specimens sustained the shear deformation until failure owing to the frictional force caused by the applied vertical load and the chemical residual friction force caused by the vulcanization.

In shear fatigue test, two of three specimens didn't show fatigue failure. In this study, additional ultimate shear test were carried out on these specimens. Figure 10 shows the load-displacement curves of specimens which

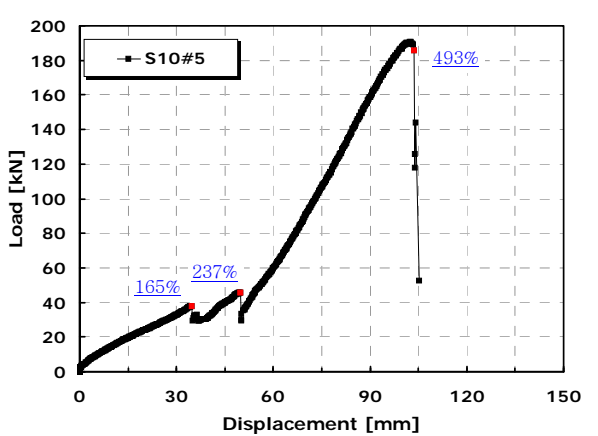

(a)

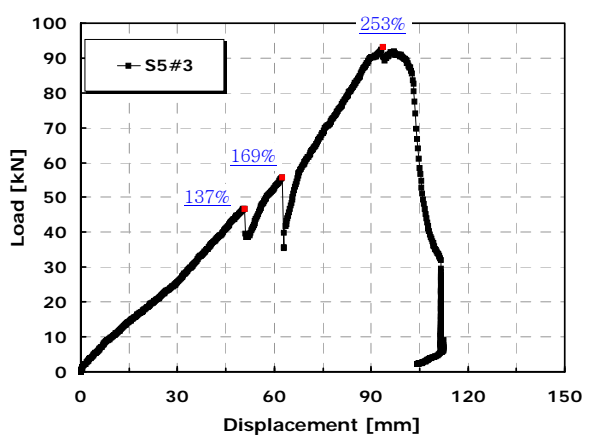

(b)

Figure 9. Shear force-displacement curve. (a) S10\#5; (b) S5\#3. 


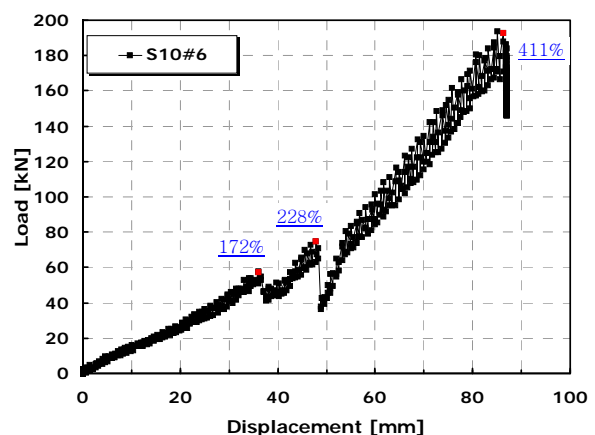

(a)

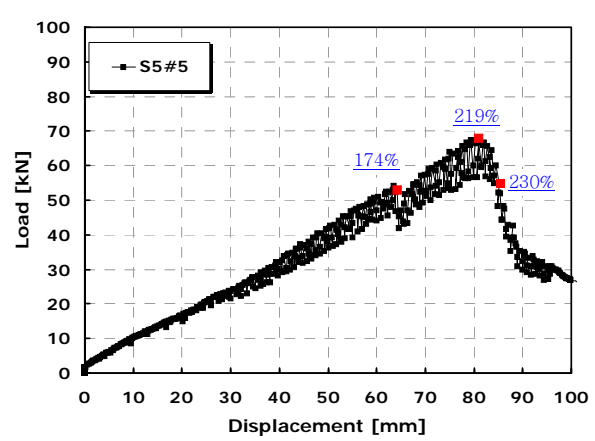

(b)

Figure 10. Shear force-displacement curve. (a) S10\#6; (b) S5\#5.

didn't failed at the shear fatigue tests. The reduction of ultimate shear performance was also observed for the bearing of doublefold elastomeric layer. And temporary loss of the load before the failure also observed.

The temporary separation of the bearing observed during the ultimate shear tests occurred within $200 \%$ of the shear strain for some specimens. Considering the allowable shear strain of KS, such temporary separation may not be problematic when the bearing is under service. However, it is recommended that the elastomeric bearings fabricated in compliance with $\mathrm{KS}$ should sustain slightly higher level of shear deformation since they may be used for the seismic design complementarily to other seismic devices despite such bearings are not seismic isolators. In addition, even if not specified in $\mathrm{KS}$, the Korean Highway Bridge Design Code [5] requires the shear strain of laminated rubber type seismic isolator to be $200 \%$ during earthquake and the Japanese Manual for Highway Bridge Bearings requires the shear strain to be up to $150 \%$ (level 1) and $250 \%$ (level 2) in the case of a seismic event. This means that when the ordinary elastomeric bearing is applied for the seismic design, unexpected impact or stress concentration may occur in the bridge system due to the separation of the bearing.

\section{Conclusion}

For elastomeric bearings to behave monolithically, the internal rubber which is located between the steel plates should be the single rubber layer. In Korea, elastomeric bearings of doublefold elastomeric layer are common practice, because the current KS doesn't restrict the use of doublefold elastomeric layer.

In this paper ultimate shear tests and shear fatigue tests were conducted on elastomeric bearings designed in compliance with KS. Some specimens are of single elastomeric layer, the other are of doublefold elastomeric layer.

The results of the shear fatigue tests and ultimate shear tests show that the elastomeric bearing whose internal rubber layer is formed by agglomeration of several rubber pads is likely to experience significant loss of its shear performances or early failure.

The elastomeric bearings adopted in this study satisfy the allowable shear strain of KS. However, separation of the surface of contact between the elastic pad and external steel plate occurred for some elastomeric bearings at shear strain of about $200 \%$. Considering that the elastomeric bearing may be used in the seismic design, such separation may provoke unexpected impacts or concentration of stress in the bridge system. Accordingly, relevant specifications should be established to prevent the fabrication of such bearing. Furthermore, assuming that the elastomeric bearing behaves monolithically without occurrence of separation at the surface of contact between the elastic pad and external steel plate, the elastomeric bearing produced in Korea was verified to secure satisfactory shear performances.

\section{Acknowledgements}

This research was supported by a grant from a Strategic Research Project (Development of design and construction system technology for hybrid cable stayed bridge) funded by the Korea Institute of Construction Technology.

\section{REFERENCES}

[1] Korea Standards Association, "KS F 4420 Steel-Laminated Elastomeric Bearings for Bridge," Korea Agency for Technology and Standards, Ministry of Knowledge Economy, Gwacheon, 1998.

[2] J. V. Muscarella and J. A. Yura, "An Experimental Study of Elastomeric Bridge Bearings with Design Recommendations," Ph.D. Thesis, University of Texas, Austin, 1995.

[3] C. Roeder, et al., "Performance of Elastomeric Bearings," Transportation Research Board, NCHRP Report 298, 1987.

[4] Japan Road Association, "Bearing Support Design Guide," Sciencebook, Seoul, 2004.

[5] Korea Road \& Transportation Association, "Korean Highway Bridge Design Code," Ministry of Construction Transportation, Seoul, 2005. 